\title{
Casual Sex, Sex Work and Unprotected Sex among Men Who Have Sex with Men in the Human Papilloma Virus (HPV) Clinical Trial -North-West Region of Tshwane, South Africa
}

\author{
Mildred R. Sebogodi', Mmampedi Huma1, Mathilda M. Mokgatle ${ }^{1 *}$, Matsontso Peter Mathebula ${ }^{2}$, \\ Maphoshane Nchabeleng 3

\footnotetext{
${ }^{1}$ Department of Epidemiology and Biostatistics, School of Public Health, Sefako Makgatho Health Sciences University, Tshwane, South Africa

${ }^{2}$ MECRU, School of Medicine, Sefako Makgatho Health Sciences University, Tshwane, South Africa

${ }^{3}$ Department of Microbiology, School of Medicine, Department of Microbiology, Sefako Makgatho Health Sciences University, Tshwane, South Africa

Email: *mathildah.mokgatle@smu.ac.za, mildred.manyane@gmail.com, matsontso.mathebula@smu.ac.za, maphoshane.nchabeleng@smu.ac.za
}

How to cite this paper: Sebogodi, M.R., Huma, M., Mokgatle, M.M., Mathebula, M.P. and Nchabelen, M. (2019) Casual Sex, Sex Work and Unprotected Sex among Men Who Have Sex with Men in the Human Papilloma Virus (HPV) Clinical Trial-North-West Region of Tshwane, South Africa. World Journal of AIDS, 9, 167-182.

https://doi.org/10.4236/wja.2019.94013

Received: October 24, 2019

Accepted: December 7, 2019

Published: December 10, 2019

Copyright $\odot 2019$ by author(s) and Scientific Research Publishing Inc. This work is licensed under the Creative Commons Attribution International License (CC BY 4.0).

http://creativecommons.org/licenses/by/4.0/

\section{(c) (i) Open Access}

\begin{abstract}
Background: The gap in the understanding of the context of the sexually transmitted infections (STIs) and risky behaviours among men who have sex with men (MSM) could lead to the development and implementation of inappropriate interventions, which could exacerbate the rapid spread of STIs, especially HIV, among MSM. The aim of the study was to qualitatively assess the understanding of the STIs and the risky sexual behaviours of men who have sex with men in the North-West region of Tshwane. Methods: An exploratory qualitative design was employed to assess the STIs and the risky sexual behaviour of the MSM population. The study participants were enrolled in an HPV clinical trial at MECRU, which is a clinical research unit at the Sefako Makgatho Health Sciences University. Data collection occurred from September 2016 to May 2017. A convenience sampling method was used and $\mathrm{n}=30$ participants were selected. Face-to-face in-depth interviews were conducted on MSM 18 years and older, using a semi-structured interview guide. Thematic content analysis was used for data analysis, using NVivo version 10 software. Results: The mean age of the sample was 26 years, and the age range was 18 to 44 years. All were unmarried, and all of them came from townships, rural villages and informal settlements in the vicinity of the clinical research unit. The high-risk behaviours noted among the majority of the MSM in this study were having multiple sexual partners and exchanging
\end{abstract}


partners, alcohol abuse, inconsistent condom-use, having unprotected anal sex, and having transactional sex. There was a high level of knowledge of STIs in the heterosexual population with poor understanding of STIs affecting MSM through anal sex. Most of the MSM played a female or bottom role, which made them vulnerable because they could not successfully negotiate condom use, and they reported that they sometimes accepted gifts or money in exchange for anal sex. Conclusion: The study concludes that the MSM in this study had casual sex, and are involved in sex work without practising safe sex. There is a need for health promotion on STIs and risky behaviours among MSM in communities as well as in health facilities for MSM in the NorthWest region of Tshwane.

\section{Keywords}

Men Who Have Sex with Men, Sexually Transmitted Infections, Casual Sex, Male Sex Work, Condom Use

\section{Introduction}

Men who have sex with men (MSM) are known as a key population because of their heightened vulnerability to sexually transmitted infections (STIs) and their risky sexual behaviour, which results in an increased risk of contracting sexually transmitted infection [1] [2] [3] [4] [5] [6] [7]. The understanding of STIs and risky behaviours among MSM remains insufficiently explored qualitatively in South Africa [8] [9]. Previous studies conducted on MSM in South Africa focused on STIs and the Human Immunodeficiency Virus (HIV) in a pluralistic approach and only a few of them have been qualitative studies designed to explore and understand STIs among MSM.

An increased prevalence and incidence of STIs such as chlamydia, syphilis and gonorrhoea, are seen in MSM as compared to the general population. The drivers of high-risk behaviours that predispose MSM to STIs and HIV include the abuse of alcohol and drugs, having multiple sexual partners, having unprotected anal intercourse even when the HIV status of the sexual partner is unknown, and having transactional sex [10] [11] [12]. Moreover, MSM are more at risk of the acquisition of STIs because of the heightened biological susceptibility in anal sex [2] [6] [13].

The gap in the understanding the context of STIs and risky behaviours among MSM could lead to the development and implementation of inappropriate interventions, which could exacerbate the rapid spread of STIs, especially HIV, among MSM [11] and catalyse the growth of the STIs and HIV among MSM. The dearth of qualitative studies limits the effectiveness of existing sexual health programmes for MSM because of the lack of the perspective and experience of the key population. Collecting data on participants' behaviour associated with the risk of acquiring HIV is important when conducting trials to determine whether the risk behaviour profiles of the participants in experimental and control study 
groups are comparable at baseline, and to provide a measure of whether they remain comparable over time [14]. We therefore conceptualized this qualitative study in the context of the sexual behaviours of MSM in an HPV clinical trial. We envisaged that the results of the study would provide locally relevant information to explain the potential reasons for the repeated STIs and antimicrobial resistance in anal STIs among MSM, since for future analysis the clinical results will be matched with the participants' behavioural data. The aim of this sub-study was to explore the sexual choices, practices, and risks behaviours of men who have sex with men in the North-West region of Tshwane.

\section{Methods}

An exploratory qualitative design was employed to assess the STIs and the risky sexual behaviour of the MSM population. Face-to-face in-depth interviews were conducted with MSM who were recruited in the trial at the SMU-MECRU, which is a clinical research unit of the microbiology laboratory at Sefako Makgatho Health Sciences University. The participants in the study were all MSM who were 18 years and older, and who lived in communities around North-West of Tshwane. The community liaison officers from MECRU were responsible for recruiting the participants from MSM hot-spots in the North-West region of Tshwane. The contact details of the participants were submitted to the Nurse Clinicians at MECRU, who invited potential participants either to report at the research unit or to be collected by the community liaisons officers to take part in the clinical trial. Potential MSM participants who had been recruited into the trial were invited to participate in the qualitative study.

For the main trial, a participant-driven sampling technique was used to recruit and enrol up to $200 \mathrm{MSM}$. For the qualitative study, a convenience sampling technique was used to recruit a sample of $n=30$ MSM from the trial participants. The sample size was determined by the saturation of data, where no new data emerged from the question asked in the interviews. Recruitment into the qualitative study occurred after the participants had undergone the clinical examination routine for the trial in the unit. Clinical examination routine included Pre and Post HIV test counselling (HIV rapid tests to be used); bloods for laboratory testing: HIV diversity testing, Hepatitis (A, B), HSV 2 and Syphilis serology; Medical history and physical examination including specific genital, anal and oro-pharyngeal examinations; rectal swabs for organisms (Neisseria gonorrhoea, Chlamydia trachomatis, Mycoplasma genitalium, HPV) andcytology (rectal smear); urethral and throat swabs for Neisseria gonorrhoea Chlamydia trachomatis, and Mycoplasma genitalium; mouth wash specimen with $5 \mathrm{ml}$ of phosphate buffer saline for HPV studies; and risk reduction counselling. Preliminary findings of the main study of $n=200$ MSM revealed that the HIV prevalence was $66.3 \%$, HSV IgM was $15.1 \%$. The prevalence of abnormal oral cytology was $41.9 \%$ (ASCL $2 \%$, ASCUS 27.3\%, LSIL 12.6\%), anorectal cytology (ASC-H 0.5\%, ASC-L 1.5\%, ASCUS 5.5\%, HSIL 2.5\%, LSIL 13.6\%) was $23.4 \%$. 
For ethical reasons and cultural sensitivity, recruitment into the qualitative study was not based on the diagnosis of the MSM. The sample included MSM who were already accessible, who were available, who willingly volunteered to participate in the study, and who were 18 years of age or older.

The researcher, who was a public health graduate student, and two research assistants who had been trained in qualitative data collection were responsible for recruiting the MSM and for conducting the in-depth interviews. Data collection occurred over a period of nine months, September 2016 to May 2017, after permission to conduct the study had been granted by the management of MECRU.

\subsection{Measures}

A semi-structured research instrument was an in-depth interview guide that included questions on the sexual choices, preferences, roles and sexual behaviours of the MSM. Demographic data were collected from the human papilloma virus (HPV) clinical trial and linked with the qualitative data. The length of the in-depth interviews ranged from 20 to 40 minutes and because of the sensitivity of the research topic, the participants were informed that they had the right not to answer questions that they perceived to be uncomfortable. The interviews were conducted in English and North Sotho, which is a common local language in the area.

\subsection{Data Analysis}

The qualitative raw data were transcribed verbatim, and the transcripts were translated from the local language into English. All transcripts were read and formatted and then imported into NVivo version 10 software. Manual coding was performed as the initial step of analysis and a codebook was developed from the five initial transcripts. The codebook was also imported into the NVivo version 10 analysis software for the application of codes. The transcripts were coded and analysed using a thematic content analysis approach.

\section{Results}

\subsection{Sample Description}

The participants in the qualitative study were 30 MSM residing in the NorthWest region of Tshwane. The majority of the population residing in the area are Africans. Hence the study sample consisted of African males. The age range of the MSM was from 18 to 44 years. The mean age of the participants was 26.8 years. As illustrated in Table 1, all the MSM in this study were not married. Only one of the 30 participants reported to be bisexual and had one child, while the rest were homosexual. The only participant who reported being bisexual also reported to currently engaging in vaginal sex, while the rest reported only anal sex. Regarding their educational level, $\mathrm{n}=19$ had completed secondary school, $\mathrm{n}$ $=8$ had dropped out from secondary school, and 2 had tertiary qualifications. With reference to their employment status, $\mathrm{n}=15$ were unemployed, $\mathrm{n}=4$ were pursuing tertiary education, and 11 were employed. Eleven out of the 30 MSM 
Table 1. Socio-demographics characteristics of MSM $(n=30)$.

\begin{tabular}{|c|c|}
\hline Characteristics & n (\%) \\
\hline \multicolumn{2}{|l|}{ Age $18-44$ years } \\
\hline Mean Age \pm SD & $26.83 \pm 7.6225$ \\
\hline \multicolumn{2}{|c|}{ Sexual orientation } \\
\hline Bi-sexual & $1(3.45)$ \\
\hline Homosexual & $29(100.00)$ \\
\hline \multicolumn{2}{|c|}{ Employment status } \\
\hline Student & $4(13.33)$ \\
\hline Employed & $11(36.67)$ \\
\hline Unemployed & $15(50.00)$ \\
\hline \multicolumn{2}{|c|}{ Sexual activities } \\
\hline Vaginal sex & $1(3.45)$ \\
\hline Anal sex & $29(100.00)$ \\
\hline \multicolumn{2}{|c|}{ Education level } \\
\hline Primary school & $1(3.33)$ \\
\hline Tertiary & $2(6.67)$ \\
\hline Secondary not complete & $8(26.67)$ \\
\hline Secondary school & $19(63.33)$ \\
\hline \multicolumn{2}{|c|}{ Number of sexual partners } \\
\hline 1 & $10(33.33)$ \\
\hline 2 & $7(23.33)$ \\
\hline 3 or more & $10(33.33)$ \\
\hline Unknown & $3(10.00)$ \\
\hline \multicolumn{2}{|c|}{ Partner's HIV status } \\
\hline Negative & $8(26.67)$ \\
\hline Positive & $8(26.67)$ \\
\hline Do not know & $11(36.67)$ \\
\hline Suspicious that positive but do not know & $3(10.00)$ \\
\hline
\end{tabular}

were not aware of the HIV status of their sexual partners and 10 out of the 30 reported to have had three or more sexual partners in the previous six months.

Using thematic content analysis the following five themes emerged from the data: Experiences and understanding of STIs among MSM; Casual relationships and multiple sexual partners as a norm among MSM; Alcohol and substance use during sexual encounters; Non-condom use among MSM; and Transactional sex among MSM. Pseudonyms are used in the excerpts given below to protect the identity of the participants.

\subsection{Experiences and Understanding of STIs among MSM}

The experiences and understanding of STIs by the MSM in this study varied. Some of the participants had the experience of acquiring STIs at some point in 
their sexual relationships. Some reported the type of symptoms they had had. The participants described their experiences in the following statements:

"The important thing is like... after having sex with this other guy, I started to get warts... from the guy who I slept with at the beginning... after having sex.... after a week... it was without a condom... You see... so I started experiencing the warts and everything. So I told the guy that this is what happened... Then I went to the clinic, then they injected me... Again even now like I am having a problem... I don't know why..." (Tefo, 20 years old).

"The other time this guy who was having sex with me, we had sex and I got sick. I had discharge from my anus. I was frightened." (Tshepo, 37 years old).

"It was around 2013... So yes... I was a versatile because I only wanted to find out and test how it felt. He penetrated me... So after he did me, I did him. So when I was having sex I discovered some discharges on my penis and other things." (Mojalefa, 19 years old).

The interview data show that some of the participants said that they had been in relationships with women prior to their realisation that they were gay, and they reported that they got attracted to, and occasionally had sex with men whom they perceived as straight and had steady relationships with women. One of the questions asked in the interview was, "In situations where a sexual partner has sexual relations with both men and women, what are the chances of MSM acquiring STIs that are specific to women?" The rationale for this question was that the trial was focusing on the types of STIs, especially the HPV, which has a high preponderance in women. Across all the participants, common responses were "I don't know" and "STI" in women? Maybe if you give me an example I would understand." However, when the participants were asked about the STI transmission risks among MSM, they were quite knowledgeable. The participants said:

"What kills us is that we don't have stable partners. So whenever we go out, we get drunk and have unprotected sex, things like that." (Kitso, 25 years old).

"I think multiple partners and not using condoms, not using condoms properly or safely and just don't know if you get it from people giving blow jobs." (Dalton, 44 years old, versatile).

"I think it's not using condom... being drunk and sleeping around with everyone." (Tshireletso, 30 years old, bisexual).

Another participant reported his views regarding the risk of STI among MSM:

"Well from my perspective most of the gay guys out there, from what I've experienced, like having sex is the first thing that comes to mind... being intimate with some guys, even when you go to clubs. Everyone wants to... 'I just want to have sex', so that's the main problem. And that's the reason why STIs spreading so much." (Motsumi, 25 years old).

\subsection{Casual Relationships and Multiple Sexual Partners is a Norm among MSM}

It is reported as the consensus among the homosexual men in this study that 
they have multiple sexual partners and engage in casual sexual relationships. When asked about the reasons for their having casual encounters, the participants made the following statements:

"I think it stems from the fact that for me personally I think meeting people who are not generally MSM who are there for whatever reasons they are there for in that relationship... only to find out that no suddenly there's a girl involved and there are other factors that were not part of the initial agreement... I think that causes ... you feel that if you have someone, its fine, it's great to be in a relationship. But it's better and less painful if you just have casual sex and carry on with your life." (Dalton, 44 years old, employed).

"Maybe it's because I don't know... maybe it's because we guys tend to be greedy and we are never satisfied with one partner I guess." (Martin, 25 years old, unemployed).

"As I said those guys are coming to us are bisexual, but the other... they have their own girlfriend on the side... When he comes to you he tells you that he's got a girlfriend... then but I've got feelings for you... they are playing with us... So it's a challenge which we come across." (Sam, 27 years old, unemployed).

Another participant reported on the reason why there were many casual sexual encounters in the gay community:

"That's why normally we will, most of gays will sleep with one man now... sleep with another one later... do one-night-stands again and again. And normally we get guys from clubs when we go there... I would say it's like prostitution in some way... because we go to tavern, we go to clubs we get there and we see a guy... he is drinking this stuff...you start thinking let me buy him his drink... I have cash let me do this to benefit sex from him." (Selby, 32 years old, employed).

With regard to casual sexual encounters, some participants reported on sleeping around within a sexual relationship:

"And then yes then the sex started... we thought sleeping with as many people as you possibly can was the thing you know... you felt wanted you felt needed because people found you attractive then you think you have given them your body." (Dalton, 44 years old).

"No I was not practising safe sex, but it came to a point where it was becoming too much and I was sleeping with different people and stuff." (Pitso, 22 years old).

"You know once you attach yourself to someone and then you start asking yourself questions like 'Why did this person choose me?'... 'Is he doing this to get something from you'... or 'Is he doing this for the fun of it?' Maybe he wants to know how this life goes... But what I do know is that we are afraid of rejection." (Selby, 32 years old).

Apart from the multiple sexual partners, casual relationships and the sleeping around, some participants described how they changed partners and moved from one relationship to another:

"I dated 2 people at the same time... I'm still dating the second one... I found 
the second one last year January." (Puseletso, 27 years old).

"I've never had like a serious one because everyone who is in the closet doesn't want to be seen that they are dating gay... so it was one of those things of dating in secrecy... then if others find out we break up and find someone else." (Bongani, 35 years old).

"Me and the guy, first guy we dated during December... So when I come back home during school holidays he didn't have time for me... So I was decided to break up with him... because he's wasting my time... After that I broke up with him... So he came back... saying 'I'm sorry for not giving you my time and all the things.' So I accepted the apology and continued to love him... even now I still love him... and then after that I was interested to another guy." (Mojalefa, 19 years old, single but having casual sex).

The MSM reported having had sex while under the influence of alcohol. It was a common occurrence in places such as clubs, taverns and pubs:

"Most of the guys I sleep with when I'm drunk I meet them in taverns, pubs." (Bongani, 35 years old, employed).

"I had sex with my cousin when I was drunk." (Selby, 32 years old, employed.)

However, the participants often reported inconsistent condoms with their partners inconsistently:

"In my sexual act sometimes I do use condom... do you know in gay life, as much as the bottom... if this guy I wanted him for so long... when I catch him... even when you are catching a fish you become excited... like I did catch a fish... so the excitement came like I did catch this person... then as time goes on... we tell ourselves let us not use condoms we would rather use lubricant." (Mojalefa, 19 years old).

"In this situation by the time we get home, I'm not very drunk... so I would have... I normally keep condoms around... and I keep in mind that whoever this is I don't want them to infect me with whatever they have... and I don't want to infect them with whatever I would have... so I try not to as much as possible fight for condoms... and I've had situations where people say 'No you don't trust me' and so on... and I was like 'No I don't know you... So I don't trust you'... but I've had burst condom on number of occasions." (Dalton, 44 years old).

\subsection{Alcohol and Substance Use during Sexual Encounters}

The participants reported having had sex while under the influence of alcohol. It was a common occurrence in places where MSM socialise, such as taverns and pubs:

"Most of the time, because we...let me put it like this...Most of the time... because we might be leaving the tavern then the shy guy will approach me while he's drunk and then I go for him..." (Sam, 27 years old, unemployed).

"This thing happens at the tavern... not a pub... at a tavern. It happens there only." (Tefo, 20 years old, employed). 


\subsection{Non-Condom Use among MSM}

Their sexual behaviours relating to non-condom use depended on the type of sexual relationship they were in, as condom use was more common with casual partners than with their regular, steady partners. Some participants made statements illustrating this:

"I won't lie... we don't often use condoms... we used a condom from the start when we started dating... from then on like we just stopped." (Sipho, 21 years old).

"It might be alcohol abuse sometime or just that you tell yourself you have been using a condom all this time... today let us not... The big challenge now is to convince my sexual partners that we have to use condoms. I also have a challenge of using condoms all the time because I sometimes don't feel like it." (Bongani, 35 years old).

"But you know sometimes maybe when you're at the house or on the road or public space and we don't have a condom." (Kitso, 25 years old).

\subsection{Transactional Sex among MSM}

Some of the MSM reported engaging in transactional sex for financial gain. The participants also described the usual sites of such casual encounters. They would have transactional sex because they needed the money:

"Will sleep with one man now... sleep with another one later... do one night stands again and again. And normally we get guys from clubs when we go there... I would say it's like prostitution in some way...because we go to tavern, we go to clubs we get there and we see a guy... he is drinking this stuff... you start thinking let me buy him his drink... I'm having cash let me do this to benefit sex from him." (Selby, 32 years old).

"I needed cash and then there was someone willing to offer me cash and then for him it was his first time... so he wanted someone with experience... Then I agreed we went to have sex. It took a while for him to be in the mood because it was his first time... Most of the time it's because of money... because they pay you to have sex with you." (Bongani, 35 years old).

"They call me and whoever has my numbers and then I just make an appointment... you make an appointment and then he tells me how much do I want like a sex worker like that." (Sam, 27 years old).

\section{Discussion}

This study was conducted among a sample of young men who have sex with men. The mean age of the sample was 26 years. The participants lived in a peri-urban area which consists of townships, rural villages and informal settlements where the residents are mostly Africans. All the participants were unmarried, only one of them was in a bisexual relationship. Twenty-two out of the 30 either knew the HIV-positive status of their sexual partners or were naïve about the HIV status of the sexual partner. Despite knowing or not knowing the sexual 
partners' HIV status, the MSM in this study mostly practised unprotected sex. The context of the MSM in this study is similar to those presented in studies conducted in two other provinces of South Africa, Limpopo and the Cape Province [15] [16] [17] and in four sub-Saharan countries, Ghana, Malawi, Botswana and Namibia [18] [19]. This picture is disconcerting since the studies cited above were conducted in the past decade, 2007 to 2017, which implies that there has been no progress towards closing the gap to mitigate the risk of contracting HIV among MSM by supporting the development of evidence-based and targeted HIV prevention programmes.

The acquisition and transmission of STIs was understood by the MSM in the study even though there was a practice of inconsistent condom-use. The findings in the study indicate that the MSM were not knowledgeable about the common types of STIs affecting MSM generally. This contributed to their risky sexual behaviour, as knowledge of STIs has been reported to be associated with condom use [16]. The more one knows about the risk of contracting STIs, the greater the likelihood of condoms use [20]. Another explanation of the existence of the association of good knowledge of HIV transmission and unprotected anal sex among men is that the good level of knowledge commonly held is about the heterosexual risk, but there is limited knowledge of the MSM-specific risk [17]. This also explains why all the MSM in this study opposed the view that MSM can acquire STIs that are specific to women.

MSM in this study reported that they had had incidents of acquiring STIs, had had casual sexual relationships, had had unprotected anal sex, multiple and concurrent sexual partners, and had used condoms inconsistently. These findings have also been reported world-wide [12] [16] [21] [22] [23]. The reasons for their engaging in a multiplicity of sexual relationships was reported to include a desire to feel good because of being wanted by many men, and a desire for physical pleasure with other men. It is common among young and unmarried MSM that they do not sustain steady and monogamous relationships [15] [17] [24].

The MSM in this study attributed having unstable relationships and multiple sexual partners to the existing culture of cheating, dishonesty, mistrust, partner sharing, and not being ready for commitment by their partners. Such findings have also been reported in other studies in the African continent [16] [23]. Moreover, dissatisfaction with having only one partner and a desire to use the partner for financial or sexual gain were also apparent in the data. The data show that economic challenges induce transactional sexual relationships for financial gain among MSM, and there is evidence in the literature that some MSM use sex as their primary source of income [21]. This corroborates the findings of other authors who concluded that there were various factors associated with engagement in transactional sex among MSM, unemployment being one of them [25]. We also found that an MSM in a transactional sexual relationship has a reduced power in the relationship as he was paid for sex, hence experience increased difficulty in negotiating condom use. Reduced power and non-condom use made the MSM more vulnerable to STIs and HIV transmission. Transactional sexual rela- 
tionships therefore involve high-risk sexual behaviours among MSM [16] [22].

The data show inconsistent condom use among the MSM and non-condom use with a regular partner, which was reported as an expression of commitment to the relationship between the sexual partners. Condom use with a casual partner reflected the fact that the relationship was still in its early stages, and that trust had not yet developed. Once the casual partner became a regular partner, the use of condoms was often discontinued. Such decisions pertain to interpersonal factors such as trust, commitment, and a perception of the risk of contracting diseases through sexual relationships. This suggests that those in committed relationships were more at risk of contracting STIs and HIV than those involved in casual relationships, as echoed in other studies [15] [16] [20] [26] [27] [28] [29]. Our data also show that the inconsistent use of condom among MSM in the study included sexual encounters which were often unplanned or occurred under the influence of alcohol, and the lack of the availability of condoms. This finding is replicated in various studies performed all over the world [21] [28] [30]. This finding was also not surprising, since the MSM in this study would meet their sexual partners at night in pubs, taverns, and clubs, which are common places of courtships for MSM, who engage in alcohol and drug use before having sex [31]. Baral et al. (2009) characterise the lack of freedom to socialise openly in daytime in the communities where MSM live, and their being manipulated to have anal sex in exchange for gifts or money as some of the human right violations that occur among MSM [17]. Alcohol use exacerbated the MSM's participation in unprotected anal intercourse and their poor condom-use negotiation, as judgement is often impeded when there is substance use. The association of alcohol use, high-risk behaviours, having multiple sexual partners and having unprotected anal intercourse is also reported in various other studies [15] [26] [28].

Receptive unprotected anal intercourse is reported to be one of the most risky behaviours in regard to the transmission of STIs and HIV. It is sixteen times more likely to lead to the transmission of STIs than unprotected vaginal intercourse, and the MSM who play the female role are more vulnerable [3] [5] [17] [24] [30] [32]. In consensus with other studies [16] [22] [33] [34] [35], our findings show that most of the MSM in our study played the female role (were the "bottoms") in the relationships, and the person who played the male role in the relationship (the "top") made the decisions on condom-use during sexual intercourse. The existence of gender roles in MSM relationships also increases the vulnerability to STI infection among the MSM, especially for those who assume the bottom role.

This study had several limitations that need to be discussed. Firstly, a convenience sampling method was used, and this increases the potential for selection bias. Therefore, the participants in this study are not necessarily representative of the whole MSM population in South Africa. The findings are not transferable to the larger population of MSM in the North-West of Tshwane either, as the sample comprised of younger men, and the study therefore does not represent 
the experiences of older men.

Secondly, there were more MSM who identified themselves as playing the female role than those who play the male role. This could be attributed to the fact that the main trial employed a participant-driven sampling technique, from which we conveniently sampled. We therefore cannot draw conclusions about MSM who do not identify as being gay or bisexual.

Thirdly, the race mostly fully represented in the townships North-West of Tshwane is African. Therefore, other races were not represented in the study. Fourthly, the participants might have under-reported on some of the questions. Also, the study was based on in-depth interviews, so some of the responses of the participants to questions about their sexual behaviours may be socially desirable responses.

\section{Conclusions}

The findings of this qualitative study highlight the individual perspective of the MSM with regard to their understanding of STIs and risky sexual behaviours. Our findings indicate that MSM engage in casual sex, sex in exchange for gifts or money, and unprotected sex. Risky sexual behaviours such as inconsistent condom use, alcohol use during sex, having multiple sexual partners, having unprotected anal sex, and having transactional sex, and inadequate understanding of the transmission of STIs lead to their being at high risk of acquiring HIV and STIs.

The findings confirm that MSM understand STI transmission among the heterosexual population but they do not attribute anal sex to STIs to occur within the heterosexual population. There is a need for an intervention that will improve protective sexual behaviours, sexual health education and health promotion about STIs and risky sexual behaviours among young MSM in the NorthWest region of Tshwane.

Health facilities should be used as settings for the distribution of sex education information on STIs among MSM, and consistent condom use awareness programmes should be offered to communities on a continuous basis. Health promotion and awareness campaigns on alcohol abuse, STIs and HIV preventative programmes targeting young MSM should be mounted for health professionals as well as for the community. Young MSM in particular must be targeted in peer-based health promotion programmes to educate them about their risky behaviours and STIs.

\section{Ethics Approval and Consent to Participate}

Prior to the in-depth interviews, the participants provided written informed consent. The participants were informed that their participation was voluntary and that they could withdraw from the study at any time if they wished to do so. All the data collected were treated as confidential and the anonymity of the participants was maintained. Ethical approval was obtained from Sefako Makgatho Health Sciences University Ethics Committee (SMUREC/H/129/2016:IR). 


\section{Consent for Publication}

Permission to use the data for publication and removing all unique identifiers from the data was sought for from the participants.

\section{Availability of Data and Material}

Transcripts or audio-recordings of the data cannot be shared in the interest of protection of the participants but trustworthiness of the data is illustrated in the way that data was analyzed, presented and interpreted.

\section{Funding}

The study was funded by the VLIR/UOS.

\section{Authors' Contributions}

MN, MRS, MH and MM conceptualized the study. MRS collected the data, MH and MM supervised data collection. MRS, MH and MM analyzed, interpreted the data and wrote the manuscript, MM finalized the writing of the manuscript, MN and MPM read and approved the final manuscript.

\section{Acknowledgements}

We thank the funders, staff members of MECRU and the participants who were willing to travel to the clinical research unit and volunteered to participate in the qualitative study. The field workers who enabled rich qualitative data are greatly appreciated.

\section{Conflicts of Interest}

The authors declare no conflicts of interest regarding the publication of this paper.

\section{References}

[1] Koblin, B.A., Husnik, M.J., Colfax, G., Huang, Y., Madison, M., et al. (2006) Risk Factors for HIV Infection among Men Who Have Sex with Men. Aids, 20, 731-739. https://doi.org/10.1097/01.aids.0000216374.61442.55

[2] Jin, F., Jansson, J., Law, M., Prestage, G.P., Zablotska, I., et al. (2010) Per-Contact Probability of HIV Transmission in Homosexual Men in Sydney in the Era of HAART. Aids (London, England), 24, 907. https://doi.org/10.1097/QAD.0b013e3283372d90

[3] Baggaley, R.F., White, R.G. and Boily, M.-C. (2010) HIV Transmission Risk through Anal Intercourse: Systematic Review, Meta-Analysis and Implications for HIV Prevention. International Journal of Epidemiology, 39, 1048-1063. https://doi.org/10.1093/ije/dyq057

[4] Beyrer, C., Baral, S.D., Van Griensven, F., Goodreau, S.M., Chariyalertsak, S., et al. (2012) Global Epidemiology of HIV Infection in Men Who Have Sex with Men. The Lancet, 380, 367-377. https://doi.org/10.1016/S0140-6736(12)60821-6

[5] McIntyre, J., Jobson, G., Struthers, H., De Swardt, G. and Rebe, K. (2013) Rapid As- 
sessment of HIV Prevention, Care and Treatment Programming for MSM in South Africa. Anova Health Institute, Johannesburg.

[6] Patel, P., Borkowf, C.B., Brooks, J.T., Lasry, A., Lansky, A., et al. (2014) Estimating Per-Act HIV Transmission Risk: A Systematic Review. AIDS (London, England), 28, 1509. https://doi.org/10.1097/QAD.0000000000000298

[7] UNAIDS (2015) UNAIDS Terminology Guidelines.

[8] Baral, S., Sifakis, F., Cleghorn, F. and Beyrer, C. (2007) Elevated Risk for HIV Infection among Men Who Have Sex with Men in Low- and Middle-Income Countries 2000-2006: A Systematic Review. PLoS Medicine, 4, e339. https://doi.org/10.1371/journal.pmed.0040339

[9] Evans, M.G., Cloete, A., Zungu, N. and Simbayi, L.C. (2016) HIV Risk among Men Who Have Sex with Men, Women Who Have Sex with Women, Lesbian, Gay, Bisexual and Transgender Populations in South Africa: A Mini-Review. The Open AIDS Journal, 10, 49. https://doi.org/10.2174/1874613601610010049

[10] Parry, C., Petersen, P., Carney, T., Dewing, S. and Needle, R. (2008) Rapid Assessment of Drug Use and Sexual HIV Risk Patterns among Vulnerable Drug Using Populations in Cape Town, Durban and Tshwane, South Africa. SAHARA-J: Journal of Social Aspects of HIVIAIDS, 5, 113-119. https://doi.org/10.1080/17290376.2008.9724909

[11] Johnson, W.D., Diaz, R.M., Flanders, W.D., Goodman, M., Hill, A.N., et al. (2008) Behavioral Interventions to Reduce Risk for Sexual Transmission of HIV among Men Who Have Sex with Men. Cochrane Database of Systematic Reviews, No. 1, CD001230. https://doi.org/10.1002/14651858.CD001230.pub2

[12] Williams, P.P., Carney, T. and Parry, C.D. (2016) Reducing Substance Use and Sexual Risk Behaviour among Men Who Have Sex with Men in South Africa. South African Journal of Science, 112, 1-5. https://doi.org/10.17159/sajs.2016/20150425

[13] Varghese, B., Maher, J.E., Peterman, T.A., Branson, B.M. and Steketee, R.W. (2002) Reducing the Risk of Sexual HIV Transmission: Quantifying the Per-Act Risk for HIV on the Basis of Choice of Partner, Sex Act, and Condom Use. Sexually Transmitted Diseases, 29, 38-43. https://doi.org/10.1097/00007435-200201000-00007

[14] Andrasik, M.P., Karuna, S.T., Nebergall, M., Koblin, B.A., Kublin, J.G., et al. (2013) Behavioral Risk Assessment in HIV Vaccine Trials Network (HVTN) Clinical Trials: A Qualitative Study Exploring HVTN Staff Perspectives. Vaccine, 31, 4398-4405. https://doi.org/10.1016/j.vaccine.2013.07.003

[15] Lane, T., Shade, S.B., McIntyre, J. and Morin, S.F. (2008) Alcohol and Sexual Risk Behavior among Men Who Have Sex with Men in South African Township Communities. AIDS and Behavior, 12, 78-85. https://doi.org/10.1007/s10461-008-9389-x

[16] Imrie, J., Hoddinott, G., Fuller, S., Oliver, S. and Newell, M.-L. (2013) Why MSM in Rural South African Communities Should Be an HIV Prevention Research Priority. AIDS and Behavior, 17, 70-76. https://doi.org/10.1007/s10461-012-0356-1

[17] Baral, S., Trapence, G., Motimedi, F., Umar, E., Iipinge, S., et al. (2009) HIV Prevalence, Risks for HIV Infection, and Human Rights among Men Who Have Sex with Men (MSM) in Malawi, Namibia, and Botswana. PLoS ONE, 4, e4997. https://doi.org/10.1371/journal.pone.0004997

[18] Stime, K.D., et al. (2017) The Cost of Diagnostic versus Syndromic Management of Sexually Transmitted Infections in the HIV Epicentre. Sexually Transmitted Infections, 93, A211.1-A211. https://doi.org/10.1136/sextrans-2017-053264.549

[19] Baral, S., Burrell, E., Scheibe, A., Brown, B., Beyrer, C., et al. (2011) HIV Risk and Associations of HIV Infection among Men Who Have Sex with Men in Peri-Urban 
Cape Town, South Africa. BMC Public Health, 11, 766. https://doi.org/10.1186/1471-2458-11-766

[20] Sandfort, T., Yi, H., Knox, J. and Reddy, V. (2013) Sexual Partnership Types as Determinant of HIV Risk in South African MSM: An Event-Level Cluster Analysis. AIDS and Behavior, 17, 23-32. https://doi.org/10.1007/s10461-012-0294-y

[21] Narayanan, P., Das, A., Morineau, G., Prabhakar, P., Deshpande, G.R., et al. (2013) An Exploration of Elevated HIV and STI Risk among Male Sex Workers from India. BMC Public Health, 13, 1059. https://doi.org/10.1186/1471-2458-13-1059

[22] Aho, J., Hakim, A., Vuylsteke, B., Semde, G., Gbais, H.G., et al. (2014) Exploring Risk Behaviors and Vulnerability for HIV among Men Who Have Sex with Men in Abidjan, Cote d'Ivoire: Poor Knowledge, Homophobia and Sexual Violence. PLoS ONE, 9, e99591. https://doi.org/10.1371/journal.pone.0099591

[23] Wagner, G.J., Tohme, J., Hoover, M., Frost, S., Ober, A., et al. (2014) HIV Prevalence and Demographic Determinants of Unprotected Anal Sex and HIV Testing among Men Who Have Sex with Men in Beirut, Lebanon. Archives of Sexual Behavior, 43, 779-788. https://doi.org/10.1007/s10508-014-0303-5

[24] Jin, F., Crawford, J., Prestage, G.P., Zablotska, I., Imrie, J., et al. (2009) Unprotected anal Intercourse, Risk Reduction Behaviours, and Subsequent HIV Infection in a Cohort of Homosexual Men. AIDS (London, England), 23, 243-252. https://doi.org/10.1097/QAD.0b013e32831fb51a

[25] Oldenburg, C.E., Perez-Brumer, A.G., Reisner, S.L. and Mimiaga, M.J. (2015) Transactional Sex and the HIV Epidemic among Men Who Have Sex with Men (MSM): Results from a Systematic Review and Meta-Analysis. AIDS and Behavior, 19, 2177-2183. https://doi.org/10.1007/s10461-015-1010-5

[26] Mimiaga, M., Thomas, B., Mayer, K., Reisner, S., Menon, S., et al. (2011) Alcohol Use and HIV Sexual Risk among MSM in Chennai, India. International Journal of STD \& AIDS, 22, 121-125. https://doi.org/10.1258/ijsa.2009.009059

[27] University of California SF (2015) Report of the South Africa Men-Who-HaveSex-with Men Data Triangulation Project. University of California, San Francisco.

[28] Bello, B., Moultrie, H., Somji, A., Chersich, M.F., Watts, C., et al. (2017) Alcohol Use and Sexual Risk Behaviour among Men and Women in Inner-City Johannesburg, South Africa. BMC Public Health, 17, 548. https://doi.org/10.1186/s12889-017-4350-4

[29] Lane, T., Raymond, H.F., Dladla, S., Rasethe, J., Struthers, H., et al. (2011) High HIV Prevalence among Men Who Have Sex with Men in Soweto, South Africa: Results from the Soweto Men's Study. AIDS and Behavior, 15, 626-634. https://doi.org/10.1007/s10461-009-9598-y

[30] McDaid, L.M. and Hart, G.J. (2010) Sexual Risk Behaviour for Transmission of HIV in Men Who Have Sex with Men: Recent Findings and Potential Interventions. Current Opinion in HIV and AIDS, 5, 311-315. https://doi.org/10.1097/COH.0b013e32833a0b86

[31] Grov, C. and Crow, T. (2012) Attitudes about and HIV Risk Related to the "Most Common Place" MSM Meet Their Sex Partners: Comparing Men from Bathhouses, Bars/Clubs, and Craigslist.org. AIDS Education and Prevention, 24, 102-116. https://doi.org/10.1521/aeap.2012.24.2.102

[32] Rebe, K.B., De Swardt, G., Struthers, H. and McIntyre, J.A. (2013) Towards' Men Who Have Sex with Men Appropriate' Health Services in South Africa. Southern African Journal of HIV Medicine, 14, 52-57. https://doi.org/10.4102/sajhivmed.v14i2.78 
[33] Morris, M. and Kretzschmar, M. (1997) Concurrent Partnerships and the Spread of HIV. Aids, 11, 641-648. https://doi.org/10.1097/00002030-199705000-00012

[34] Knox, J., Yi, H., Reddy, V., Maimane, S. and Sandfort, T. (2010) The Fallacy of Intimacy: Sexual Risk Behaviour and Beliefs about Trust and Condom Use among Men Who Have Sex with Men in South Africa. Psychology, Health \& Medicine, 15, 660-671. https://doi.org/10.1080/13548506.2010.507772

[35] Hoff, C.C., Chakravarty, D., Beougher, S.C., Neilands, T.B. and Darbes, L.A. (2012) Relationship Characteristics Associated with Sexual Risk Behavior among MSM in Committed Relationships. AIDS Patient Care and STDs, 26, 738-745.

https://doi.org/10.1089/apc.2012.0198

\section{List of Abbreviations}

HIV-Human Immunodeficiency Virus

HPV_Human Papilloma Virus

MSM-Men who have sex with men

STIs-Sexually Transmitted Infections

SMU-Sefako Makgatho Health Sciences University 